\title{
SISTEM INFORMASI PARIWISATA PANTAI PANDAWA BERBASIS WEB
}

\author{
I Made Bisma Aditya, I Putu Yoga Ananta, Kadek Nuada Yusgiantara, dan Rama Dian Rizki \\ Pratama
}

ITB Stikom Bali

\begin{abstract}
This research is a development of the advancement of information technology that implements part of information technology, namely the use of websites. This study aims to introduce Pandawa Beach and other things related to this beach to the public by visiting the website that we created. This study uses the waterfall modelling system development method and several data collection techniques, namely observation, interviews, documentation, and literature. The results of this study conclude that the web-based coastal tourism information system built in this study is the first information system used to promote coastal tourism in Badung Regency, Bali.

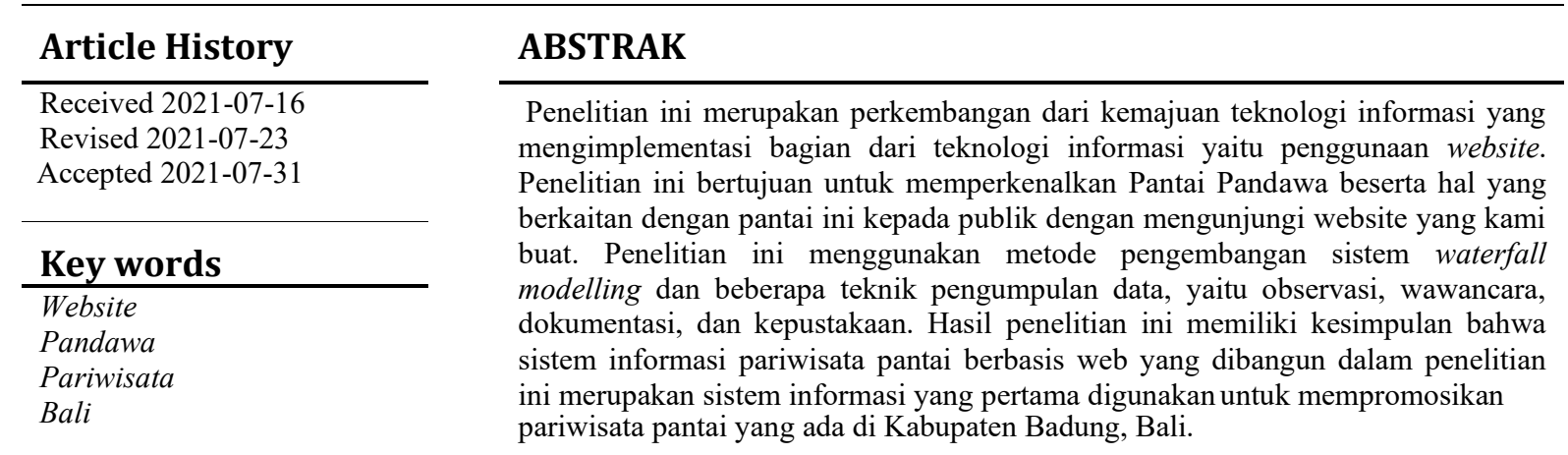

\section{PENDAHULUAN}

Pariwisata merupakan sektor yang penting untuk dikembangkan sebagai salah satu sumber dari pendapatan daerah tersebut, karena selain memberikan keuntungan bagi tempat wisata itu sendiri juga memberikan keuntungan pada infrastruktur yang menjadi pendukungnya, seperti rumah makan, pedagang-pedagang kecil, penjual oleh oleh, dan juga tempat menginap yang ada disekitarnya. Pulau Bali merupakan ikon pariwisata yang sangat di kenal luas oleh dunia. Bali menjadi salah satu pulau yang di pilih para wisatawan yang hendak berwisata ke Indonesia, karena Bali dikenal oleh banyak wisatawan memiliki keindahan alam yang tidak dimiliki oleh pulau pulau lain di Indonesia salah satu nya yaitu Pantai Pandawa.

Pantai Pandawa ini terletak di Kuta Selatan, Kabupaten Badung, Bali. Keindahan Pantai Pandawa ini menjadi daya tarik bagi para wisatawan untuk berkunjung, selain pemandangannya yang bagus dan pasir nya yang putih, banyak sekali kegiatan kegiatan yang bisa dilakukan di Pantai Pandawa ataupun kegiatan seni yang dilakukan warga sekitar di Pantai Pandawa. Dengan adanya perkembangan Teknologi Informasi ini, keindahan Pantai Pandawa perlu dihimpun dalam suatu website yang memiliki tampilan yang menarik dan sekaligus sebagai pilihan wisatawan untuk mengunjungi Pantai Pandawa. Oleh karena itu kami ingin membuat suatu website yang dimana dapat memudahkan akses informasi para wisatawan yang ingin berwisata seperti harga tiket masuk, lokasi Pantai Pandawa dan hal lainnya yang berkaitan tentang pantai ini. Dan sangat diharapkan bisa menunjang objek wisata Pantai Pandawa ini agar lebih maju lagi dan selalu menjadi tujuan para wisatan setiap berwisata ke Bali melalui website yang kami buat.

Pentingnya dibuat website ini adalah dapat menghemat biaya dalam penyampaiannya dan dapat di akses oleh semua pengguna di seluruh dunia dengan jaringan internet. Hal ini akan mendorong meningkatnya jumlah kunjungan wisatawan, dan akan meningkatkan aset daerah dan 
juga perekonomian masyarakat sekitarnya. Berdasarkan hal di atas, maka akan dibuat sebuah web pariwisata dengan judul, "Merancang Sistem Informasi Pantai Pandawa berbasis Web"

\section{TINJAUAN PUSTAKA}

Sistem Informasi (SI) adalah kombinasi dari teknologi informasi dan aktivitas orang yang menggunakan teknologi itu untuk mendukung operasi dan manajemen. Dalam arti yang sangat luas, istilah sistem informasi yang sering digunakan merujuk kepada interaksi antara orang, proses algoritmik, data, dan teknologi. Dalam pengertian ini, istilah ini digunakan untuk merujuk tidak hanya pada penggunaan organisasi teknologi informasi dan komunikasi (TIK), tetapi juga untuk cara di mana orang berinteraksi dengan teknologi ini dalam mendukung proses bisnis. Ada yang membuat perbedaan yang jelas antara sistem informasi, dan komputer sistem TIK, dan proses bisnis. Sistem informasi yang berbeda dari teknologi informasi dalam sistem informasi biasanya terlihat seperti memiliki komponen TIK. Hal ini terutama berkaitan dengan tujuan pemanfaatan teknologi informasi. Sistem informasi juga berbeda dari proses bisnis. Sistem informasi membantu untuk mengontrol kinerja proses bisnis.

Alter berpendapat untuk sistem informasi sebagai tipe khusus dari sistem kerja. Sistem kerja adalah suatu sistem di mana manusia dan/atau mesin melakukan pekerjaan dengan menggunakan sumber daya untuk memproduksi produk tertentu dan/atau jasa bagi pelanggan. Sistem informasi adalah suatu sistem kerja yang kegiatannya ditujukan untuk pengolahan (menangkap, transmisi, menyimpan, mengambil, memanipulasi dan menampilkan) informasi. Dengan demikian, sistem informasi antar-berhubungan dengan sistem data di satu sisi dan sistem aktivitas di sisi lain. Sistem informasi adalah suatu bentuk komunikasi sistem di mana data yang mewakili dan diproses sebagai bentuk dari memori sosial. Sistem informasi juga dapat dianggap sebagai bahasa semi formal yang mendukung manusia dalam pengambilan keputusan dan tindakan. Sistem informasi merupakan fokus utama dari studi untuk disiplin sistem informasi dan organisasi informatika.

Sistem informasi adalah gabungan yang terorganisasi dari manusia, perangkat lunak, perangkat keras, jaringan komunikasi dan sumber data dalam mengumpulkan, mengubah, dan menyebarkan informasi dalam organisasi. Sistem informasi adalah suatu sistem di dalam suatu organisasi yang mempertemukan kebutuhan pengolahan transaksi harian, mendukung operasi, bersifat manajerial dan kegiatan strategi dari suatu organisasi dan menyediakan pihak luar tertentu dengan laporan - laporan yang diperlukan. Terdapat empat langkah dalam membangun suatu sistem informasi, yaitu menentukan serta mengetahui masalah, menyediakan solusi alternatif, memilih solusi, dan mengimplementasikan solusi yang dipilih. Ketiga langkah pertama disebut sebagai analisis sistem.

\section{METODE}

Dalam mengumpulkan data-data yang dibutuhkan untuk pelaksanaan penelitian ini, digunakan beberapa teknik pengumpulan data sebagai berikut:

A. Observasi, yang dimaksud dalam penelitian ini adalah pengamatan langsung yang ditujukan pada situasi secara umum, berupa segala sesuatu yang berlangsung pada Dinas Pariwisata dan Ekonomi Kreatif Kabupaten Badung, Bali.

B. Wawancara, ditujukan kepada personil yang dianggap memahami data-data dan informasi yang ada di Dinas Pariwisata dan Ekonomi Kreatif Kabupaten Badung, Bali, khususnya data dan informasi tentang objek wisata pantai pandawa yang ada didesa adat kutuh, Bali.

C. Dokumentasi, mengumpulkan dokumen yang memuat informasi tentang objek wisata pantai yang ada di Kabupaten Banggai Kepulauan, serta dokumen-dokumen tertulis mengenai Dinas Pariwisata dan Ekonomi Kreatif Kabupaten Badung, Bali. 
D. Kepustakaan, memperoleh berbagai informasi teoritis dari para peneliti terdahulu maupun para ilmuan sebagai suatu kerangka teori yang dijadikan acuan dan perbandingan dalam penelitian ini. Metode analisis yang digunakan dalam penelitian ini adalah metode kualitatif, yaitu suatu prosedur penelitian yang menghasilkan data deskriptif; ucapan atau tulisan dan perilaku yang dapat diamati dari orang-orang (subyek) itu sendiri .

Metode kualitatif memiliki tiga tahap analisis data sebagai berikut:

a) Reduksi data, proses penyederhanaan data-data yang diperoleh dari lapangan. Data tersebut diseleksi dan difokuskan pada informasi yang benar-benar dibutuhkan sehingga diperoleh abstraksi data mentah.

b) Paparan data, data atau informasi yang telah dihasilkan akan dideskriptifkan secara sederhana kedalam bentuk naratif.

c) Kesimpulan, tahap terakhir dari analisis data. Peneliti mengambil inti dari pemaparan data sehingga menjadi pernyataan yang singkat dan padat tetapi mengandung makna mendalam yang menjadi sebuah kesimpulan sementara sehingga kesimpulan tersebut dapat menjawab permasalahan yang dihadapi dalam penelitian.

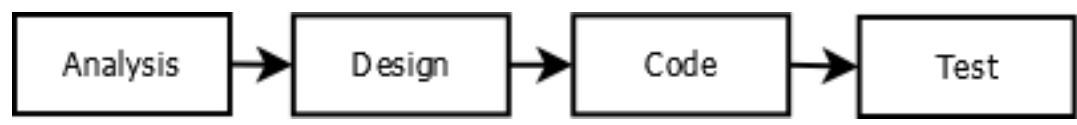

Gambar 1. Model Sejuensi Linier

Metode pengembangan sistem yang digunakan dalam penelitian ini adalah waterfall modelling, karena dengan mengunakan metode ini diharapkan dapat menghasilkan sistem yang lebih sempurna dan memungkin adanya evaluasi kembali terhadap proses pengembangan sistem. Adapun metodologi pengembangan sistem adalah metode-metode, prosedur-prosedur, konsepkonsep dalam pekerjaan, aturan-aturan, dan postulat-postulat yang akan digunakan untuk mengembangkan suatu sistem informasi. Sedangkan pengembangan diartikan sebagai aktifitas untuk menghasilkan sistem informasi berbasis komputer untuk menyelesaikan suatu persoalan organisasi atau memanfaatkan kesempatan-kesempatan yang timbul. Adapun tahap-tahap pengembangan sistem dalam menggunakan waterfall modelling sebagai berikut :

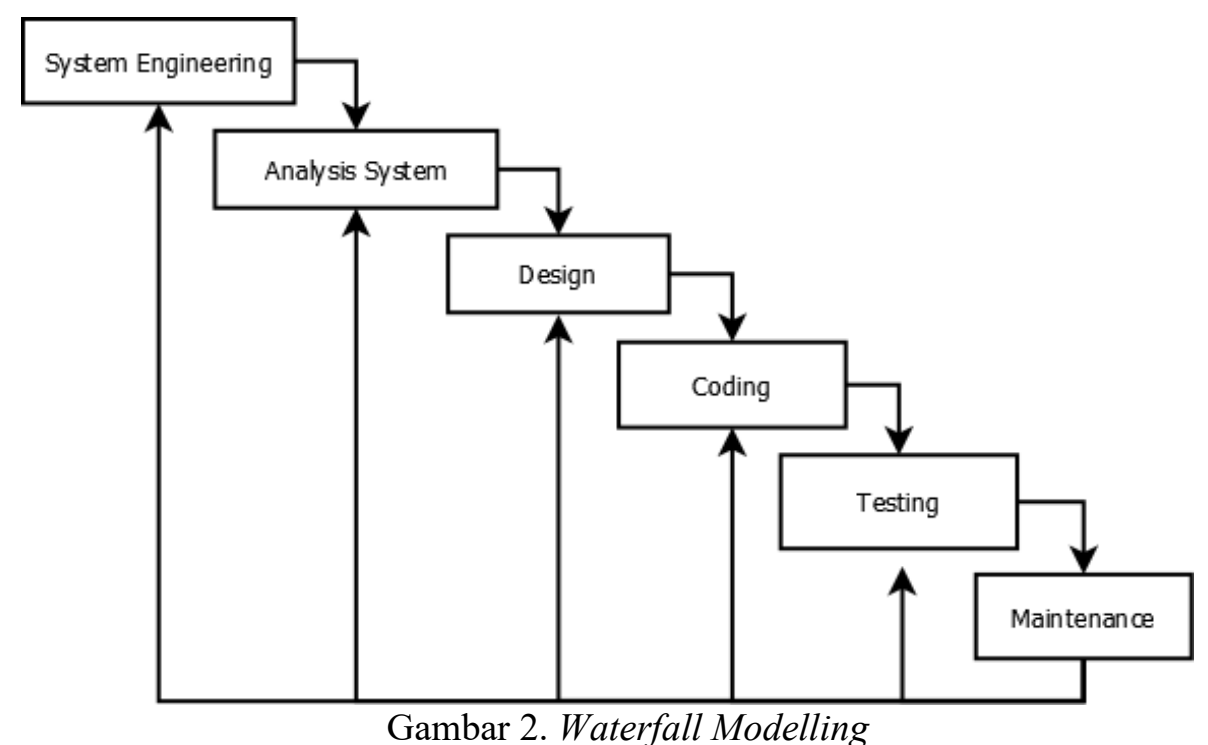

HASIL DAN PEMBAHASAN

Pembahasan Data I 
Berdasarkan hasil pengamatan ditemukan bahwa sistem yang sedang berjalan pada Dinas Pariwisata dan Ekonomi Kreatif Kabupaten Badung, Bali adalah proses dengan sistem manual. Hal ini dapat diketahui dengan adanya penyampaian informasi tentang pesona pariwisata yang disajikan dalam bentuk modul-modul informasi, iklan, brosur, bahkan masyarakat mendatangi langsung Dinas Pariwisata dan Ekonomi Kreatif Kabupaten Badung, Bali untuk memperoleh informasi yang dibutuhkannya. Sistem yang diberlakukan pada Dinas Pariwisata dan Ekonomi Kreatif Kabupaten Banggai Kepulauan tersebut dapat digambarkan sebagai berikut:

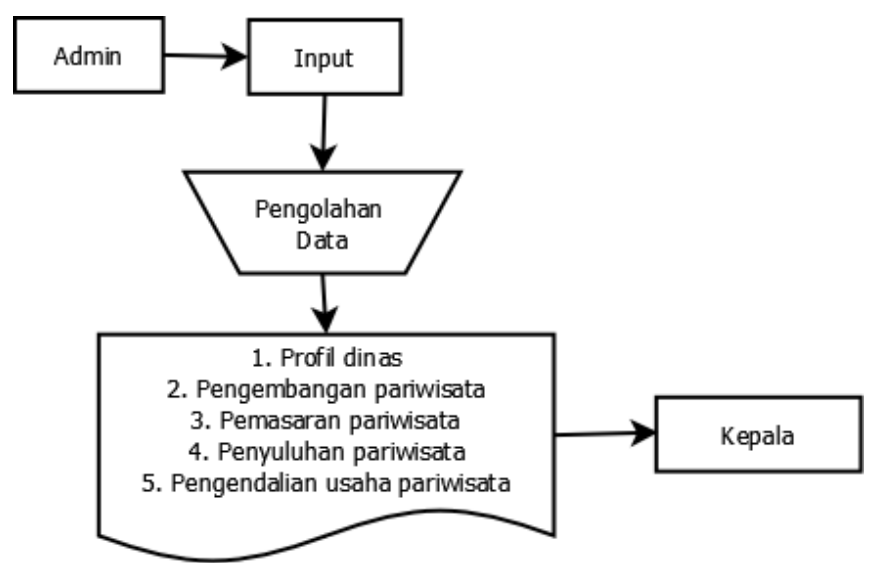

Gambar 3. Sistem Informasi Dinas Pariwisata dan Ekonomi Kreatif Kabupaten Banggai Kepulauan

Dalam gambar diatas nampak bahwa admin atau operator menginput data selanjutnya diproses secara manual melalui microsoft word atau microsoft power point. Manual yang dimaksud disini yaitu tidak terotomatisasi atau dengan kata lain setiap entitas berdiri sendiri sehingga membutuhkan waktu yang cukup lama dalam prosesnya sehingga terdapat beberapa kelemahan pada sistem yang sedang berjalan sebagai berikut:

a. Sistem pengolahan data-data potensi pariwisata Kabupaten Badung, Bali masih manual dan dalam pengolahan data. Sistem manual ini rentan terhadap resiko kehilangan data karena kesalahan manusia atau bencana.

b. Adanya kesulitan dalam mencari data-data atau informasi terbaru tentang potensi pariwisata pantai Kabupaten Badung, Bali dan informasi yang ada terkadang tidak sesuai atau belum dikelola dengan baik.

c. Pengembangan potensi pariwisata pantai belum optimal karena data-data yang ada tidak semuanya terkumpul dan belum sesuai.

\section{Pembahasan Data II \\ Definisi Pantai Pandawa}

Pantai Pandawa adalah pantai yang letaknya di ujung Desa Kutuh di Uluwatu. Tadinya pantai ini bernama pantai Kutuh dan untuk mencapai surga tersembunyi ini dibutuhkan kerja keras menuruni tangga atau melewati jalan sempit diantara karang. Kemudian pemerintah menguyurkan dana untuk komersialisasi penuh akan potensi pariwisata di pantai Kutuh. Pantai ini pun kemudian disulap menjadi Pantai Pandawa. Sangat populer adalah kata yang tepat untuk mendeskripsikan pantai Pandawa saat ini. Kepopulerannya bahkan bisa dibilang sudah melampaui pantai-pantai lain di Sanur, Jimbaran atau Nusa Dua yang sudah terlebih dahulu tampil dihadapan publik. Tidaklah mengherankan kenapa pantai ini cepat mendapatkan kepopulerannya, bentangan pasir putih dengan air biru jernih dan ombak yang tidak terlalu besar akan benar-benar memanjakan pengunjung pantai ini. Fasilitas pariwisata dan akses yang mudah menjadi faktor lain kenapa turis domestik dan luar negeri berbondong-bondong datang ke Pantai 
Pandawa. Untuk mencapai pantai Pandawa bukanlah hal yang susah. Rute ke arah Pura Uluwatu adalah patokan utama. Mulai dari perempatan setelah GWK, ikuti jalan ke kanan menuju Ungasan sampai ada jalan membelah karang di sebelah kiri. Ikuti jalan utama karena cukup panjang sampai ada persimpangan yang memiliki papan penunjuk arah "Pantai Pandawa" ambil kembali arah kanan jalan. Jalan beraspal yang mulus diantara tebing besar akan membawa anda langsung ke Pantai Pandawa. Yang unik dari pantai ini adalah ceruk-ceruk di tebing dimana masing-masing dihiasi patung para Pandawa dari Epik terkenal Hindu, Mahabharata. Dari tebing para Pandawa, anda bisa melihat bentangan luas pasir putih dan ombak biru jernihnya yang menyihir mata. Disini pula telah disediakan tempat parkir cukup luas untuk mobil, motor dan bus-bus besar. Pantai Pandawa bisa dibilang cukup aman untuk aktivitas berenang karena ombaknya sering kali tidak terlalu besar. Bahkan penyewaan kano pun tersedia bagi mereka yang ingin mengekplorasi laut dengan cara berbeda. Untuk surfing biasanya para surfer akan memilih bagian Pandawa yang pantainya lebih sempit karena ombak yang ditawarkan lebih menantang. Tapi kemudian, bagaimana untuk mereka yang datang hanya sekedar berelaksasi. Jangan khawatir karena sepanjang garis pantai telah disiapkan sunbeds dibawah payung-payung besar untuk mereka yang ingin mandi matahari. Sunbeds itu tentu saja disewakan. Fasilitas lain yang tersedia di pantai Pandawa adalah tempat penitipan barang dan toilet di wantilan besar. Kemudian untuk mereka yang ingin melepas dahaga atau sekedar menikmati kudapan kecil, di areal jalan berpaving telah berjejer kedai-kedai kecil yang tentu saja hadir membuat semuanya jadi lebih mudah. Bisa dibilang Pantai Pandawa cocok untuk mereka yang ingin menemukan pantai yang tidak kalah indah atau bahkan lebih dari Kuta dan Seminyak tapi dengan fasilitas penunjang yang baik serta akses jalan yang gampang. Pantai Pandawa terletak di daerah kisaran antara Nusa Dua dan Uluwatu. Pantai Pandawa Kutuh, pantai pasir putih ini menjadi favorit wisatawan domestik saat liburan di Bali.

\section{Keindahan Pantai Pandawa}

Pantai Pandawa atau juga disebut dengan sang perawan yang ada di Bali Selatan, karena pantai ini masih sangat alami dengan air laut nya yang jernih. Pasir putihnya yang halus nan lembut membuat mata anda akan terkesima melihat keindahan pantai ini. Bahkan saat ini, kebanyakan yang berkunjung ke pantai pandawa ini adalah para wisatawan domestik yang ingin melihat secara langsung pantai baru ini. Pantai Pandawa, kata pandawa jika diambil dari cerita mitologi mahabarata adalah merupakan anak-anak pandu. Mengapa pantai ini disebut dengan pantai pandawa, karena pada salah satu sisi tebing dalam menuju pantai ini terdapat jejeran patung-patung dari para pandawa juga dewi kunti. Anda dapat berfoto disetiap patung ini bersama teman atau keluarga anda. Selain sebagai objek wisata, pantai ini juga bisa dimanfaatkan sebagai tempat berolahraga air. Ombak di pantai ini relatif cukup tenang, hamparan air laut ini tidak sampai menuju ke garis pantai. Selain para pengunjung, banyak para penduduk lokal yang membudidayakan rumput laut dikawasan pantai ini. Mereka sudah memulai pekerjaan tersebut sejak 30 tahun yang lalu jauh sebelum pantai ini populer.

\section{Potensi Alami Pantai Pandawa}

a. Potensi tebing untuk melengkapi kebutuhan pengunjung agar bisa berlama lama di seputaran tebing, akan dibangun sebuah coffee shop dengan model minimalis sehingga tidak mengganggu pemandangan, dengan penambahan pembangunan coffee shop ini diharapkan pengunjung dapat menikmati keindahan laut sambil menikmati coffe dan lainnya, serta diharapkan dapat meningkatkan pendapatan Desa Kutuh. 
b. Potensi pesisir dan pasir putih kawasan pesisir yang cukup Panjang sangat memungkinkan dikelola untuk berbagai kegiatan seperti Penyewaan Longchair, voli Pantai, outbound, wedding party, shooting, dan pementasan atraksi budaya.

c. Sunrise adalah merupakan Panorama Alam Pagi Hari yang sangat exotic sering menjadi moment sangat indah. Pantai Pandawa memiliki sunrise hampir sepanjang bulan, yang kedepan dapat dimanfaatkan untuk memperkaya panorama daya tarik wisata pantai Pandawa.

d. Sunset merupakan panorama alam sore hari, moment yang selalu ditunggu - tunggu oleh pengunjung karena keindahan. Pantai Pandawa yang memiliki pontensi sunset, dan untuk bulan-bulan tertentu dapat dipadukan dengan pementasan seni tarian kecak.

\section{Potensi Buatan Pantai}

Pandawa tidak hanya memiliki potensi alami, tetapi juga potensi buatan. Berikut akan dijelaskan mengenai potensi buatan yang ada di Pantai Pandawa, meliputi:

a. Patung Pandawa, merupakan simbol dari nama Pantai ini, patung-patung ini dibangun di dalam tebing sesuai dengan konsep Pandawa Lima terjebak didalam Gua Galagala saat berperang melawan para Kurawa.

b. Voli Pantai, merupakan potensi wisata buatan berada dibibir Pantai Pandawa, dan dialokasikan di bagian barat Pantai Pandawa, yaitu berada didepan tempat tim pesona bahari yang sarana dan prasarana sudah disediakan oleh tim pesona bahari.

c. Fasilitas, merupakan potensi buatan dimana diarea kawasan pantai pandawa, telah tersedia berbagai macam fasilitas yang bisa memenuhi kebutuhan setiap pengunjung yang datang, yaitu:
a) Restaurant (Restoran)
b) Art shop
c) Kios-Kios Penjualan makanan dan minuman
d) Toilet
e) Tempat Spa
f) Tourist Information Center.
g) Sunbed

\section{KESIMPULAN}

Sistem informasi pariwisata pantai berbasis web yang dibangun dalam penelitian ini merupakan sistem informasi pertama yang digunakan untuk mempromosikan pariwisata pantai yang ada di wilayah Kabupaten Badung. Maksud dari pembangunan sistem informasi pariwisata pantai berbasis web ini agar Dinas Pariwisata dan Ekonomi Keatif Kabupaten Badung dapat mengelola data-data potensi wisata yang ada secara efektif dan efisien sehingga dapat memberikan informasi terbaru tentang pariwisata pantai yang ada di Kabupaten Badung kepada masyarakat dengan cepat dan mudah.

\section{DAFTAR PUSTAKA}

[1]De Du Jaya 2014 , "Sejarah Pantai Pandawa Desa Kutuh” terletak di Desa Kutuh, Kec. Kuta Selatan, Kab. Badung. http://pandawaline.blogspot.com/p/blog-page_5752.html

[2] Wayan Suadnyana 2021 , "Pantai Pandawa di Desa Kutuh-Peta Lokasi dan Harga Tiket Masuk 2021" . https://www.water-sport-bali.com/pantai-pandawa/

[3]Kadek Elda Primadistya 2014 , "Pantai Pandawa". http://kadekelda.blogspot.com/2014/05/pantai-pandawa-bali.html

[4] Mas Sugeng 2014-2016 , "Pantai Pandawa Bali, Tempat Wisata Tersembunyi di Bali Selatan". http://www.idtempatwisata.com/2014/11/pantai-pandawa-bali-tempat-wisata.html

[5] Sisil 2017 ,"Sistem Informasi Pariwisata". https://si.ittelkom-pwt.ac.id/2017/09/12/sisteminformasi-pariwisata/ 
[6]Yasin K 2019 , "Pengertian Mysql, Fungsi dan Cara Kerjanya". https://www.niagahoster.co.id/blog/mysql-adalah/

[7]Evomaya 2021 , "Pengertian Database Serta Fungsi dan Jenis-Jenisnya". http://www.evomaya.com/articles/60/pengertian-database-serta-fungsi-dan-jenis-jenisnya/

[8] Omar Pahlevi , Astriana Mulyani , Miftahul Khoir 2018, "Sistem Informasi InventoriBarang Menggunakan Metode Object Oriented". https:/ejurnal.lppmunsera.org/index.php/PROSISKO/article/download/587/612/

[9] Dewa Made Mertayasa , Abd. Rizal Yambee. Vol.3 No.1 Januari-Juni 2017, "Sistem Informasi Pariwisata Pantai Berbasis Web Pada Dinas Pariwisata dan Ekonomi Kreatif Kabupaten Banggai Kepulauan". stmik-binamulia.ac.id 